\title{
Costs and benefits of research
}

\section{By T. V. L. Ulbricht, Agricultural Research Council, i6o Great Portland Street, London $W_{\mathrm{I}}$}

The biggest problem in the management of research is to decide what research to do. The problem becomes quite crucial when, as in recent years, our research resources are strictly limited and, in fact, more or less static in real terms. In other words, if we want to embark on something new, we have to stop something else. How do we decide what to stop, and how do we decide which of a number of possible lines of research we will pursue?

Perhaps we cannot approach these questions in quite the same way for all types of research. By type of research I mean whether it is basic or applied etc. and will use the definitions used in my own organization (Ulbricht et al. 1972) which are derived from those in the Dainton Report (Command 4814 , 1971). Briefly stated they are: fundamental research is concerned with the acquisition of new knowledge, without being able to see if and how that knowledge may be applied; strategic research is concerned with the acquisition of new knowledge with the specific purpose of applying it; applied research is concerned with the application of existing knowledge to the solution of a defined practical problem.

If we restrict ourselves to Government-financed research, we see that the answers to the questions: who decides? where is the research done? who pays? how much? are not the same for the three types. Under the Rothschild principle, the 'customer' decides what applied research is to be done, how much he can afford, and pays for it. The research is done by various contractors; the contractor may be a Research Council or it may be another part of the Government department (the 'customer') funding the research. The decision about what fundamental research is to be done is taken by the scientists themselves (in Universities) or by various committees on which scientists play a leading role (Research Councils), and it is funded by the UGC and/or the Science Vote. As far as the latter is concerned, the Advisory Board on the Research Councils advises on how much each Research Council is to receive, subject to Treasury approval. In between comes strategic research, which is carried out in some Government departments as well as Universities and Research Councils, and which is mainly funded from the Science Vote although some parts of it, because of its close links with concurrent applied work, may be commissioned under the Rothschild principle. In this case, therefore, different groups may be deciding what is to be done, and how much.

Some organizations, like my own, carry out all three types of research. Is it useful to begin with the question: how much fundamental research should we do, and how much applied? I think that any active research scientist will agree that it is not. There is no formula that will answer the question, no magic figure like ' $10 \%$ 
for free research' which is not completely arbitrary, and the question is meaningless when applied to a large area of research like agriculture. In a more narrowly defined field, like nutrition, it may be more meaningful, because one can ask a question like: what are the most important problems? If it is clear that some fundamental knowledge is lacking on which the further development of the whole subject depends, then more fundamental research is what is needed.

In my opinion there is, however, a value in knowing roughly how much fundamental or applied research one is doing, and keeping an eye on how that pattern is changing. For example, if my Council were doing $90 \%$ applied research, then I-and many others, I am sure-would be worried as to where, in the years to come, completely new ideas for research and for new techniques were to come from; not only would we be dependent on the outside world for ideas but we would not be able to attract sufficient first-class innovative scientists and to train them to become effective research leaders. The same thing applies to institutes though here a wider spectrum is valid because of their different subject areas and traditions. However, it is my own opinion that a good mix of all three types of research within one institute is a good thing and that applied and fundamental research are often closer than is realized. But if scientists doing applied and fundamental work never meet and talk, how will this be seen? (Of course, getting them to talk to each other may sometimes be a problem!)

But in a large organization like the Agricultural Research Council, with thirty institutes, how can one know what the proportions of fundamental, strategic and applied research are? Also, while we may know precisely the total expenditure at one institute, because each has its own budget, how do we know how much is spent across the Agricultural Research Service on nutrition and how much within that field, on different dietary constituents? The point is that several institutes are working on animal nutrition but working on other things as well. There are fields in which the situation is even more complicated; no less than twelve institutes are concerned with various aspects of grassland research, for example. So we decided in 1972 to introduce a project system (Ulbricht, 1971). The research at each institute is described in terms of individual projects, which are classified in a variety of ways, according to whether the work is fundamental, strategic, or applied; according to which agricultural commodity, plant or animal species the work is related to (e.g. man, wheat, poultry, eggs, milk); the research area (e.g. breeding, cultivation, disease, nutrition) and so on. In addition, key-words are available so that one can retrieve, for example, all work on electron microscopy or all work on pollution. Each project is costed, from a simple record kept by each scientist once a month stating how his time was allocated between the different projects on which he works. All this is computerized and the system has been designed for flexible retrieval, so that a print-out for a given research area can be produced structured according to the aspect of the research pattern that those reviewing or planning research may require.

Well, all that is just mechanics, but at least we can now see more clearly what we are doing in our large organization, and also, what it is costing. But are these cost 
figures in fact any help to us in deciding on priorities? Since my Council is concerned with agriculture, its research must serve the community by helping the industry in its production of food, by improving yield, quality and efficiency. There must, therefore, be some relation between the amount of research done and the output value of that sector of the industry to which the research relates. It would be silly, wouldn't it, to spend as much on tomatoes as on wheat, or as much on rabbits as on cattle? By dividing research expenditure on different commodities by their output value one obtains ratios which can be compared. This is not to say, and no one is saying it, that there is some known 'right' value for this ratio, or that the ratios should be the same. But the comparisons are interesting and raise questions. The highest values we found were for maize and for fruit. In the case of maize, this seemed fully justified, since research was helping to establish and spread a crop that was new to the UK and whose present output value is still relatively low. In fruit, the situation appeared to have persisted for decades and not to be justified. It is quite true that growing fruit is a much more sophisticated and complicated business than growing wheat, and much more expensive, but then, that is reflected in the value of the product and so the ratio takes care of that. My point is that such figures make one stand back and think: is this pattern right? Will it be right in the years to come?

We also wondered whether costs could be related to benefits. There was, after all, a well-established technique of cost-benefit analysis and a number of papers had been published using it in the field of agricultural research, giving, in some cases, very high benefit to cost ratios indeed. That was rather appealing because it seemed we might use the technique to strengthen the case for agricultural research. In our study of this subject, conducted mainly by my colleague Mr Wise (Wise, 1975; Wise \& Ulbricht, 1975; Wise, 1977; Wise, 1978), I must say that we became more and more disillusioned with this approach and not just because of the nonsense that was almost foisted onto the nation with regard to a third airport for London.

In the first place, we found that there did not exist a 'well-established technique of cost-benefit analysis', but a number of techniques with quite significant differences, each with its adherents and opponents. This is not the place to examine these differences in techniques, so let me just say that they are not trivial and can have a marked effect on the value of the ratio calculated. The question of what social discount rate to adopt is just one of them.

Then there is the fact that in many of the calculations actually carried out, the 'costs' are taken to be the research costs only; implementation costs are ignored. In agricultural research, plant breeding is an example where the costs of implementation can sometimes be ignored. Once a new variety has been bred and its superiority shown in trials, a farmer may be able to adopt it quite simply, although in the case of hybrid maize, with a considerable increase in resource costs. Suppose, however, it were to be shown that hay is, after all, superior to silage in the diet of dairy cattle because it affects milk composition or the quality of butter in some particular way. Making hay in our climate, especially in the western 
regions where most of the grassland is, is a tricky business, so perhaps barn-drying should be more widely adopted. That requires a certain investment. But many farmers, especially the ones with larger herds, have invested quite heavily in silos and other equipment for making silage. We have here what is in fact an example of a more typical situation, namely, that the adoption of a new research finding into practice requires a change in the production system which may involve investment, change or reorganization of labour, and so on. The implementation costs may be considerable and, sometimes, very difficult to estimate.

In addition, there may be 'intangible' costs, that is, costs which cannot be quantified (e.g. pollution from a new pesticide; the effect on health of a new breadmaking process) and the same may be true of benefits, or they can be quantified but not evaluated in any market sense (e.g. a reduction in lives lost). One can treat an individual as an economic unit, and assess his ill health in terms of loss of production and consumption, cost of health care and his pension, because all these losses and costs have, in the end, to be paid by the community in taxes, higher prices or insurance premiums. But an individual who dies leaves a bereaved family and friends, or chronic ill health diminishes his life as a human being; we are no longer talking about quantity, but about quality. If we are considering research in nutrition in relation to a major disease, like coronary heart disease, we can produce impressive figures about the number of people who die, the cost of intensive care units and so on. However, such figures do not help us to decide how much to spend on research on fat or fibre in the diet, or whether the money would be better spent on trying to improve the public's understanding of nutrition, or on more intensive care units.

Another problem is that of distributional effects. Who benefits? In agriculture the progressive farmer, the 'early adopter', often benefits initially at the expense of other farmers, often at the expense of the poorer ones. But after a time, when nearly all farmers have adopted the new method, crop variety or whatever it is, production has risen and prices fall. The farmers are worse off and the consumer benefits, or it is the manufacturer of a new machine or pesticide who benefits. There is no way in which cost-benefit analysis can take account of this; in social terms, we cannot offset a loss of $£_{1} 1000$ to a subsistence farmer by a gain of $£_{0} 1000$ to an agrochemical company.

In the long term, the social consequences of changes in technology have been, and are, profound. Agriculture has become, and is still becoming, more capital- and less labour-intensive, but this process has perhaps reached the point now where the viability of rural communities is seriously affected, and village schools and shops are disappearing. Some countries, Norway and the Netherlands, for example, have decided that this process has gone far enough and that if it goes any further the social costs to the nation are likely to outweigh the benefit of what is called more 'efficient' production. It seems to be not at all understood in the UK that the much-maligned Common Agricultural Policy has been deliberately used, especially in Germany, to support marginal, small and 'inefficient' farmers precisely to maintain rural communities and to maintain the care of the landscape. 
A final point about cost-benefit analysis is that all the papers published give $e x$ post analyses. Bearing in mind all the qualifications $I$ have mentioned, consider now the problem of carrying out ex ante analyses for a number of projects which are to be compared in order to decide on priorities. Instead of actual figures we now have to estimate how long the research will take, with how many staff, and the likelihood of success. Then there may be implementation costs, and we have to estimate benefits. But, for me, it is the importance of the qualitative aspects that can never be quantified that rules out this narrow approach. Truly, money isn't everything.

Most of the examples I have quoted are from agriculture, partly because I am familiar with it and partly because it does provide some relatively clear examples to illustrate a point. But now let us consider human nutrition. Imagine someone in the early years of this century trying to carry out an ex ante analysis of research on diet in relation to beriberi or pellagra. The consequences of scientific discoveries cannot be foreseen, neither for good nor, unfortunately, for evil.

To illustrate how priorities are actually determined, let me mention the World Food and Nutrition Study of the National Research Council of the US (Ulbricht, 1978). I 500 people contributed ideas to the report. There were fourteen study teams (some with up to four sub-groups) involving over 200 scientists, administrators and industrialists. The steering group held meetings with groups of foreign experts in Thailand, Kenya, Austria and Columbia and consulted every conceivable international and federal agency and many private organizations. Apart from those meetings in romantic places, I am irresistably reminded of the workings of our own post-Rothschildean Joint Consultative Organization which advises my Council, MAFF and DAFS on the priorities for research in agriculture and food.

Since a quantitative approach like cost-benefit analysis is impossible, one must rely on the judgement, intuition and experience of those responsible for the management of research. The question then arises whether it would not be better, as well as much simpler, to rely on the judgement of scientists themselves. Do others really know better than they do and make better judgements than they do? Does there exist a 'customer' who meets the Rothschild criterion of knowing what he wants? I think that the high level of government-funded research and public disquiet about the real 'benefit' (in the widest sense, to include effects on the quality of life) of the technology derived from it means that accountability must be a feature of the organizational structure. However, it should be flexible enough to give scientists their head in more fundamental work, while exercising more control at the applied end of the spectrum.

For our own organization, to encourage a more systematic approach to the selection of priorities, we drew up a list of criteria as a guide-line. Most of them are not relevant to nutrition, but some are; for example, consumers' welfare; feasibility; acceptability by the food industry and consumers; urgency and timeliness; and factors like availability of staff and other resources etc. I think that a special effort to draw up a list of criteria which could guide those concerned with 
decisions on priorities in research on human nutrition would be very worthwhile.

Essentially scientific research provides those responsible for national policies with a variety of options. Scientists should try, as far as they can, to draw attention to some of the possible consequences of adopting a new result or a new technology. For example, meat substitutes from plant or single-cell protein do not contain the long-chain polyunsaturated fats present in meat, and so there may be an effect on nutrition. It seems to me that this points not only to the fact that more nutritional research is definitely needed, but also more study and analysis of different ways of implementing a policy. If it is agreed, for instance, that many people in the UK would benefit from eating less sugar and saturated fat and more cereal fibre, what means could we adopt to bring this about? What would be the consequences for the food industry? In Sweden the food industry has actively cooperated in trying to help the Government to implement just such a policy. Personally I am glad that the Centre for Agricultural Strategy is interesting itself in such questions, but I wonder if it is enough.

\section{REFERENCES}

Command 4814 (1971). A Framework for Government Research and Development. London: HMSO.

Ulbricht, T. L. V. (1971). In Resource Allocation and Productivity in National and International Agricultural Research. [T. M. Andt and V. W. Ruttan, editors]. Minneapolis: University of Minnesota Press.

Ulbricht, T. L. V. (1978). Review of World Food and Nutrition Study, National Research Council, National Academy of Sciences. Food Policy, 3, 155.

Ulbricht, T. L. V., Dodd, F. H. \& Wise, W. S. (1972). Nature, Lond. 240, 427.

Wise, W. S. (1975). Research Policy, 4, 246.

Wise, W. S. (1977). $R$ \& $D$ Management, 8, 29.

Wise, W. S. (1978). $R$ \& $D$ Management, 8, 185 .

Wise, W. S. \& Ulbricht, T. L. V. (1975). Paper presented to Third Working Conference of Directors of Agricultural Research, OECD, Paris. 